\title{
Visualization of local degradation processes in coated metals by means of scanning electrochemical microscopy in the redox competition mode
}

\author{
J.J. Santana+, J. González-Guzmán, L. Fernández-Mérida, S. González and R.M. \\ Souto*, \\ Department of Physical Chemistry, University of La Laguna, E-38205 La Laguna \\ (Tenerife, Canary Islands), Spain \\ ${ }^{+}$On leave from the Department of Process Engineering, University of Las Palmas de Gran \\ Canaria, Campus Universitario de Tafira, E-35017 Las Palmas de Gran Canaria, Canary
} Islands, Spain.

\begin{abstract}
$\underline{\text { Abstract }}$
Herein, the redox competition mode of scanning electrochemical microscopy (RC-SECM) has been applied to in situ monitor the local reactivity arising from a circular holiday operated in a painted metal. The metal-coating system consisted of a carbon steel substrate coated with an epoxy-polyamine polymeric film containing glass flakes as pigment. The present work demonstrates the possibility to use RC-SECM for investigation of the corrosion reactions occurring when protective coatings are applied on a metal surface without the addition of a redox mediator to the experimental system. Oxygen reduction was employed to monitor the reactive metal-polymer system, though the onset of a redox competition for this redox species between the SECM tip and the bare metal inside the holiday could be found in certain conditions. Whether attack predominated inside the holiday or the system became non reactive depended on the composition of the test electrolyte, with borate ions acting as corrosion inhibitor.
\end{abstract}

Keywords: Corrosion; Organic coatings; Scanning electrochemical microscopy; Iron dissolution; Oxygen reduction. 


\section{Introduction}

Metallic materials are often protected against corrosion by coating them with polymeric films which act as a physical barrier to separate the metal from the aggressive agents present in the environment to which they are exposed. In this way, the metal/coating system can benefit of the good mechanical properties of the metals and metallic alloys, whereas gaining effective anticorrosion resistance at the same time. Corrosion in coated metals usually results from the combination of various processes [1,2], namely the existence of defects in the coating, the penetration of the corrosive agents from edges, losses of adherence and the corrosive attack to the metal. Additionally, the reaction may be accelerated by aggressive ions present in the solution phase. In fact, non-defective films applied on metals are known to delaminate after some time, which indicates that species from the environment may diffuse either through microscopic pores in the coating or even through the polymer matrix [3].

Unfortunately, the mechanisms of the corrosion processes that take place at defect-free coated metals, and of delamination in the vicinity of defects, are not yet completely known. These processes usually initiate from small defects present in the coating, such as holes or flaws produced during the handling of the material, accidental impacts, or even during the process of manufacture itself. Also defect-free coatings are known to deteriorate due to the penetration of water and aggressive agents from the environment, leading to the onset of blistering and/or delamination of the paint film. In fact, water uptake by coatings from electrolytes of varying composition is a major topic of investigation because of its contribution to the early steps of coating delamination. Organic coatings generally exhibit a rather high permeability to water [1,3] and to oxygen [4] despite their resistance to the flow of ions [5].

One of the microelectrochemical techniques which may be used to study the degradation processes for coated metals is the scanning electrochemical microscope (SECM), a method that couples scanning probe techniques with electrochemistry [6,7]. This technique exhibits high spatial resolution, and is applicable to both insulating [8-13] and conducting surfaces [14] when operating in the feedback mode. This technique consists in the movement of an ultramicroelectrode tip (UME) parallel to the surface of the sample inside an electrochemical cell to characterise the topography and redox activity of the solid/liquid interface. The UME and the sample may be independently biased as working electrodes with a bipotentiostat, and eventually the sample be left unbiased at its spontaneous open circuit 
potential in the medium. A faradaic current is measured at the UME when it is biased with sufficient potential for a redox mediator (i.e., an oxidizable/reducible species) in the solution, to undergo a charge transfer reaction:

$$
\text { Red } \rightarrow \text { Ox }+ \text { ne }^{-}
$$

The resulting faradaic current is controlled by diffusion, and depends strongly on the tipsample separation [6]. That is, at sufficiently small distances between the UME and the unbiased sample, some hindrance to the diffusion of the redox mediator is produced by the sample, and variations in the current measured at the probe can be related to changes in the tip-sample distance. Unfortunately, the electrochemical mediators usually employed in scanning electrochemical microscopy might be contraindicated for the investigation of the systems and processes of interest in corrosion science, as interference with the electrochemical reactions involved in them can not be discarded. An alternative route consists in the operation of the SECM in the sample generation-tip collection mode (SG-TC) [6], or the use as electrochemical mediator of some species already present in the electrolyte and which may eventually participate in the corrosion reactions too. In the first case, the soluble ionic species resulting from the anodic oxidation of a metal may be detected at the tip by adequately selecting a potential value at which they are either reduced or further electrooxidized. In this way, it has been possible to detect the occurrence of localized corrosion processes [15], and to measure local variations in the extent of metal corrosion $[16,17]$. In the second case, advantage can be taken of soluble oxygen in the electrolytic phase as electrochemical mediator, since it is an electroactive molecule, thus alleviating the need for the addition of a redox mediator $[18,19]$. In the case of freely corroding systems, soluble oxygen directly participates in the corrosion processes through electroreduction at the cathodic sites. Therefore, the tip and the sample under investigation compete for the same redox species in solution [20], and the scanning electrochemical microscope is to be operated in the redox competition mode [21].

Herein, we demonstrate the capabilities of RC-SECM to sense polymer inhomogeneity and electrochemical activity in polymer coated metals during the early stages of coating degradation. The technique has been employed in the negative feedback and the redox competition modes using oxygen as redox mediator to investigate the interfacial processes that occur. Thus, local surface activity can be mapped without adding any redox mediator to the electrolyte solution. Specifically, we report SECM images of complex electrochemical 
behaviour that occurs on metallic substrates protected by organic coatings in the vicinity of a holiday when exposed to an electrolyte solution.

\section{Experimental}

\subsection{Materials}

Carbon steel plates were employed as metallic substrates. Metal surfaces were carefully washed in acetone, ethanol and doubly-distilled water, and then dried prior to the coating process. The samples were painted in the laboratory with a withdrawing technique using an accurate speed motor and a system of gears. Coated specimens were allowed to cure at room temperature and humidity for 10 days prior to testing. The coating material was a two-component epoxy-polyamine film containing glass flakes as pigment supplied by Sigma Coatings (Amsterdam, The Netherlands). The coating thickness was measured with a MegaCheck FN Coating-Thickness-meter (List-Magnetik GmbH, Germany), and was found to be $60 \mu \mathrm{m}$. Artificial circular defects in the organic coating were produced in selected samples by using a driller to produce a circular holiday of approximately $200 \mu \mathrm{m}$ diameter.

The sample was located at the bottom of a small flat cell [20], thus exposing the coated side upwards to the test solution. The electrolyte covered the specimen under investigation by ca. $4 \mathrm{~mm}$. Platinum microelectrodes were employed as SECM tips. They were prepared from $10 \mu \mathrm{m}$ diameter platinum wires sealed in glass. An $\mathrm{Ag} / \mathrm{AgCl} /$ saturated $\mathrm{KCl}$ reference electrode and a platinum wire used as counter electrode were also introduced in the small electrochemical cell, which was placed inside a Faraday cage.

Testing was performed during immersion in electrolyte solutions at the spontaneously developed open circuit potential of the samples. The electrolytes considered were $0.1 \mathrm{M} \mathrm{KCl}$, $0.1 \mathrm{M} \mathrm{Na}_{2} \mathrm{SO}_{4}$, and $0.1 \mathrm{M} \mathrm{Na}_{2} \mathrm{~B}_{4} \mathrm{O}_{7}$ aqueous solutions. They were made from analytical-grade reagents and doubly-distilled water. All measurements were performed at ambient temperature in the naturally aerated solutions.

\subsection{Experimental procedure}

The SECM experiments were carried out using a Scanning Electrochemical Microscope built by Sensolitycs (Bochum, Germany), controlled with a personal computer. 
The electrochemical interface was a bipotentiostat, though the system was operated in a threeelectrode configuration since the coated sample was left unbiased for the duration of the experiments.

Oxygen was used as electrochemical mediator at the tip. The reduction of oxygen at the microelectrode was used to establish the height of the tip over the coated surface, and then to image the surface in situ. Oxygen reduction in aqueous solution involves heterogeneous charge transfer processes coupled with homogeneous chemical reactions [22]. On a $10 \mu \mathrm{m}$ platinum microelectrode, the cyclic voltammogram recorded at a scan rate of $0.10 \mathrm{~V} \mathrm{~s}^{-1}$ in 0.1 $\mathrm{M} \mathrm{KCl}, 0.1 \mathrm{M} \mathrm{Na}_{2} \mathrm{SO}_{4}$ and $0.1 \mathrm{M} \mathrm{Na}_{2} \mathrm{~B}_{4} \mathrm{O}_{7}$ air-saturated aqueous solution depicts a single voltammetric wave at potential values negative to $-0.20 \mathrm{~V}$ vs. the $\mathrm{Ag} / \mathrm{AgCl} / \mathrm{saturated} \mathrm{KCl}$ reference electrode (see figure 1), which corresponds to oxygen reduction through an overall four electron reduction process to produce hydroxide ions [23]:

$$
\mathrm{O}_{2}+2 \mathrm{H}_{2} \mathrm{O}+4 \mathrm{e}^{-} \rightarrow 4 \mathrm{OH}^{-}
$$

Consequently, oxygen could be monitored at the tip of the SECM by setting the potential of the microelectrode at $-0.60 \mathrm{~V} v$ s. the $\mathrm{Ag} / \mathrm{AgCl} /$ saturated $\mathrm{KCl}$ reference electrode to enable the diffusion-limited oxidation of oxygen at the tip.

The establishment of the operating tip distance over the sample was performed in relation to the intact coating. Distant areas, namely in excess of $300 \mu \mathrm{m}$ from the holiday, were selected to measure the approach curve of the electrochemical mediator, in order to secure that oxygen would be the only redox species transformed at the tip, without the interference of other redox species which would be generated inside the holiday in the event of corrosion. The approach curve was obtained by slowly approaching the surface with the tip and simultaneously recording the measured current at the microelectrode $v s$. $Z$ displacement as described elsewehere [10]. In brief, after the corresponding approach curve was obtained, it was modelled assuming that the reduction of the mediator at the surface was under kinetic control [24]. In this way, the true distance between the tip and the substrate could be determined for the height at which the microelectrode displacement was stopped when recording the approach curve. In our experiments the microelectrode was stopped when the measured current was equal to $75 \%$ of the steady-state value in the bulk of the electrolyte [19]. SECM maps were obtained by rastering the substrate surface at a constant height of 15 $\mu \mathrm{m}$ from the surface at a scan rate of $30 \mu \mathrm{m} \mathrm{s}^{-1}$. This height actually corresponds to 1.5 tip diameters, and it was chosen to prevent the tip from either scratching the surface or even 
crashing due to unavoidable tilt of the sample for the rather big portions of the surface imaged in the experiments described below (typically $1000 \mu \mathrm{m} \times 1000 \mu \mathrm{m}$ in $X$ and $Y$ directions directly over the diameter of the circular defect). Greater surface resolution could be achieved with our system by selecting significantly smaller surfaces for imaging, and rastering the tip over the sample at heights equivalent to one tip diameter or even less. In this case, the effect of tilt is less dramatic as it is experienced on bigger regions. Yet, the experiments were conducted with a somewhat higher height in order that both the holiday and a portion of the surrounding coated surface could always be imaged in the same SECM map. All the 3D maps shown were recorded by shifting the microelectrode tip from left to right (i.e., they were built as a composition of $\mathrm{X}$ displacement lines, which were stepwise shifted in the $\mathrm{Y}$ direction).

\section{Results and discussion}

The electrochemical activity and the topographic changes associated with the onset of degradation reactions from the holiday operated in the polymer-coated carbon steel were investigated by scanning arbitrary areas of the samples for different exposure times in three selected aqueous environments, namely $0.1 \mathrm{M} \mathrm{KCl}, 0.1 \mathrm{M} \mathrm{Na}_{2} \mathrm{SO}_{4}$ and $0.1 \mathrm{M} \mathrm{Na} 2 \mathrm{~B}_{4} \mathrm{O}_{7}$. The solutions were open to air, thus naturally aerated, and the samples were left unbiased to attain their corresponding open circuit potentials in each electrolyte. Since the tip potential was set at $-0.60 \mathrm{~V}$ vs. the $\mathrm{Ag} / \mathrm{AgCl} /$ saturated $\mathrm{KCl}$ reference electrode, changes in the current values measured at the microelectrode for the electroreduction of oxygen when located over the coated metal were directly related to the distance between the tip and the surface directly below it, thus responding to topographic features of the coating film discovered as the microelectrode passed above them. On the other hand, corrosion at the holiday in the organic coating could occur when the sample was exposed to the aerated electrolytic solution, and it resulted in the formation of Fe(II) species in the anodic half-cell reaction, whereas the cathodic process consumed dissolved oxygen from the solution phase. Thus, when the tip was rastered above uncoated regions, the development of corrosion reactions at the unprotected bare metal led to the consumption of oxygen at the cathodic sites, and the electrochemical reactivity of those zones could thus be monitored from the current measured at the tip through a redox-competition process [21]. 


\subsection{SECM characterization of samples during their exposure to $0.1 \mathrm{M} \mathrm{Na}_{2} \mathrm{~B}_{4} \mathrm{O}_{7}$ solution}

Figure 2 shows 3D maps of surface topography obtained for two immersion times of the polymer-coated carbon steel sample in $0.1 \mathrm{M} \mathrm{Na}_{2} \mathrm{~B}_{4} \mathrm{O}_{7}$ air-saturated aqueous solution. Two types of electrochemical response at the SECM-tip could be expected during the passage of the UME over the defective sample. Firstly, a negative-feedback effect should be observed when the tip passed over the intact polymeric film because the free diffusion of oxygen to the tip would be greatly hindered by the proximity of the specimen with independence of the length of time the sample was exposed to the test environment.

Secondly, a redox competition effect could be expected to occur within the holiday, as result of a competition between the tip and the steel surface inside the defect, which is directly exposed to the electrolyte as demonstrated by the SEM microphotograph given in figure 3, which corresponds to a sample before exposure. But a decrease in the tip current due to redox competition is not found for this system when the UME passed over the holiday at any immersion time. On the contrary, enhanced faradaic currents were measured at the tip every time it reached the border of the holiday, clearly indicating that greater amounts of soluble oxygen became available from the electrolyte volume inside the hole, and because the specimen was no longer hindering the diffusion of oxygen from the bulk. Therefore, no competition for oxygen reduction was established between the steel surface at the bottom of the holiday and the tip, and the metal did not effectively corrode in the borate-containing aqueous environment.

This observation was further demonstrated when SECM maps were recorded for narrower surface areas focused on the holiday as depicted in figure 4. They represent an area of $1000 \mu \mathrm{m} \times 10 \mu \mathrm{m}$ in $X$ and $Y$ directions directly over the diameter of the circular defect. Four different zones are clearly evidenced at the earlier stages of immersion corresponding to figures $4 \mathrm{~A}$ and $4 \mathrm{~B}$. Zone I corresponds to the intact polymer outside the defect, and the current measured at the tip directly correlates to the surface topography in the negative feedback mode of the SECM. Zone II is encountered when the tip starts to scan over the holiday at a constant height. A sharp current peak is first described, though the current quickly decreases to attain the value typical for oxygen electroreduction at the tip in the bulk of the electrolyte (zone III), that is, the current measured when there is hemispherical diffusion towards the UME surface. Finally, as the tip leaves the holiday and passes over the polymeric film again, the current measured at the tip decreases to attain the same negative feedback regime observed in Zone I. 
At longer exposures, namely for times longer than $170 \mathrm{~min}$, Zone II was no longer observed because the behaviour as the tip passed over the holiday closely matched the bulk regime. Thus, only three zones are observed from the maps shown in figures $4 \mathrm{C}-4 \mathrm{E}$. Zones I and III exhibit depleted currents corresponding to a negative feedback regime for the tip over an insulating polymeric surface, whereas Zone II extends over the holiday. The hemispherical diffusion regime is only attained as the tip is sufficiently far from the holiday borders, and the current values measured over the centre are very close to those in the bulk of the electrolyte. Therefore, no competition for oxygen electroreduction has occurred between the tip and the bare metal substrate inside the circular defect operated in the coating. No net corrosion occurred within the holiday in the borate-containing electrolyte even after 24 hours exposure to the test environment. On the other hand, asymmetry in the scan lines, which becomes more noticeable at longer exposures (cf. Figures 4C-4E) originates from the movement of the tip towards and outwards the holiday at the relatively fast scan rate employed to record the maps in figures 3 and 4 which extended over big surface areas of the sample instead of just one scan line (cf. Figure 4 in reference [20]). The reason for such effect arises from the tip advancing into a gradually more depleted concentration zone as the microelectrode consumes oxygen species from the neighbourhood.

In summary, when the defective sample was imaged with the SECM through oxygen electroreduction during its immersion in $0.1 \mathrm{M} \mathrm{Na}_{2} \mathrm{~B}_{4} \mathrm{O}_{7}$ air-saturated aqueous solution, all the information from the 3D maps is exclusively topographic. The furrow in the coating running from left to right at the centre of the images presented in figure 2 corresponds to an imperfection of the sample arising from its manufacturing, and it was also evidenced in the SEM micrograph given in figure 3 taken at the retrieved sample. Furthermore, it can be observed that the procedure of drilling a hole through the polymeric film to the underlying carbon steel substrate has been produced slow enough that no protrusions were observed around the hole.

\subsection{SECM characterization of samples during their exposure to $0.1 \mathrm{M} \mathrm{Na}_{2} \mathrm{SO}_{4}$ solution}

SECM images were used to collect surface information in the course of the corrosion process inside the holiday when the defective coated metal was immersed in $0.1 \mathrm{M} \mathrm{Na}_{2} \mathrm{SO}_{4}$ solution. Figure 5 displays the changes occurring in the SECM maps from the sample for one day. The same area has been scanned for each sample during the experiment. Within the first 
hour of exposure, the maps exhibit a situation closely resembling to that described above for the sample exposed to the borate-containing electrolyte. SECM maps matched the topography of the sample at earlier exposures, and even some minor deformations could be observed at the borders of the holiday which resulted from the drilling process. Those features were observed as regions of smaller oxygen availability, thus effectively protruding from the surface coating into the electrolyte. For exposures in excess of one hour, the swelling of the coating from the holiday masked the protrusions at the border of the holiday (cf. figure 5B). This effect is considered to originate from the delamination front below the polymer at the bottom of the holiday almost exclusively, since no significant changes in the topography of the coating could be observed at locations far from the defect even at the longest exposures.

On the other hand, the amount of oxygen available for electroreduction when the tip scans above the holiday decreases appreciably with the elapse of time, even to the situation that the current measured at the tip is significantly smaller than that over the coating despite the thin layer of oxygen-containing electrolyte available in the near field regime. Such evolution is more clearly deduced from the inspection of the scan lines taken over the centre of the holiday at various immersion times given in figure 6 . This behaviour is due to the onset of a redox competition for dissolved oxygen between the tip and the advancement of the corrosion reaction inside the holiday which effectively consumes oxygen in the cathodic microcells originated on the bare metal. In fact, the topographical contour of the holiday is imaged only with the scan line from the map recorded immediately after immersion (i.e., time exposure of $5 \mathrm{~min}$ ), whereas in those measured for 1 and 3 hours exposure, the extent of the corrosion reaction is already enough to effectively compensate the diffusion of oxygen from the bulk electrolyte as compared to the amount available in the negative feedback regime over the intact coating. Next, at longer exposures, the corrosion reaction is observed to progress more rapidly with time, with the result of smaller currents being measured above the holiday from subsequent scans. Thus, the maps in figure 5 exhibit the changes in the electrochemical activity occurring inside the holiday with the advancement of time due to the corrosion reactions on the bare metal. The extent of the corrosion reaction inside the holiday was readily observable using a metallographic microscope to view the sample after retrieval from the electrolyte (not shown here), as well as the precipitation of corrosion products inside the holiday.

\subsection{SECM characterization of samples during their exposure to $0.1 \mathrm{M} \mathrm{KCl}$ solution}


SECM images were also recorded during the exposure of a coated sample with a holiday to $0.1 \mathrm{M} \mathrm{KCl}$ solution. Selected maps are shown in figure7, and the central scan lines from the maps are plotted in figure 10. The establishment of corrosion reactions inside the holiday when exposed to this electrolyte, with the result of a redox competition towards oxygen electroreduction is also observed in this case, quite similar in general terms to that previously described for the tests in $0.1 \mathrm{M} \mathrm{Na}_{2} \mathrm{SO}_{4}$ solution (cf. Section 3.2). A significant diminution in the amount of oxygen available inside the holiday is observed after 90 minutes exposure, and it is even smaller than the amount above the surrounding coating in the map recorded after 2 hours, which is an indication that the extent of the corrosion process is bigger in the chloride-containing electrolyte than in the sulphate-containing solution for the same exposures (cf. figure 5).

Despite the reported similarities between the processes for the samples immersed in either chloride or sulphate electrolytes as revealed by SECM, a significant difference must be noticed too. Swelling of the coating originating from the holiday and extending below a furrow in the coating was observed for exposures longer than 2 hours as shown in figure 7B. The furrow was present in the coating from the manufacturing operation, and it was observed as a topographical depression extending from left to right in the SECM map of figure 7A. Higher currents were measured at the tip when it passed over the furrow in the negativefeedback regime of the SECM, and thus it corresponded to an area of a slightly thinner coating applied over the metal. The furrow becomes less noticeable with the elapse of time and eventually could not be observed after 4 hours exposure. At this stage, the current measured at the tip over the furrow is smaller than the values recorded over the intact coating, and it is also smaller than the current measured over the holiday. It must be realized that two different principles are operating in the latest comparison, for the reduction over the holiday results from the redox competition for oxygen reduction between the tip and the corroding metal inside the defect, whereas the smaller currents measured over the furrow arise from a negative feedback effect, and thus they correspond to a region in the coating surface that progresses in the electrolyte phase further approaching the tip that is scanned at a constant height. Therefore, it can be considered that swelling of the coating occurs from the delamination front at the holiday progressing below those regions with a thinner coating occurring at the furrow. This behaviour was not observed in the case of the furrow produced in the sample exposed to the borate-containing solution as described above, a test environment in which no corrosion of the sample from the holiday was observed. Yet, such 
swelling occurs in all directions from the delamination front inside the holiday, and it can be observed to extend further distance from the holiday borders with the elapse of time, as it can be observed from the inspection of the scan lines depicted in figure 8, which were taken in a direction perpendicular to that described by the furrow.

\section{Conclusions}

The metal-coating system under consideration exhibited different behaviours when exposed to various electrolytes, namely sodium borate, sodium sulphate and sodium chloride. They were evidenced by scanning electrochemical microscopy operating with dissolved oxygen as redox mediator at the ultramicroelectrode tip, and the following conclusions were derived:

(1) Negative feedback operation of the SECM is maintained when the tip is scanned over the non-defective coating outside the holiday regardless the composition of the electrolyte. Hindered diffusion of oxygen due to the proximity of the coated sample is responsible for the reduction in the redox currents measured at the ultramicroelectrode as compared to the current measured for the same process when the tip is placed in the bulk of the electrolyte. In this regime, topographical changes occurring during the degradation process could thus be imaged with high resolution.

(2) Negative feedback operation can also be employed to monitor the advancement of the delamination front below the coating from a holiday, as result of the onset of corrosion processes at the bare metal inside the holiday, this effect being more notorious in the chloridecontaining environment.

(3) Bigger electroreduction currents are measured at the tip when it is scanned over the holiday when the bare metal exposed inside does not corrode. The absence of a corrosion process within the holiday makes the dissolved oxygen in the solution to be available for reaction at the SECM tip exclusively, and the dimensions of the holiday, approximately one order of magnitude bigger than those of the probe, are sufficient to restore the bulk electrolyte condition over the defect.

(4) Redox competition between the tip and the bare metal inside the holiday occurs when the tip passes over the defect after the onset of the corrosion reaction. Oxygen is then consumed at the cathodic sites in the corroding system, and thus a volume with depleted oxygen concentration is found by the rastering tip. In this case, the SECM images do not 
show the topography of the holiday, but they depict the advancement of the electrochemical reactions involved in the corrosion process.

\section{Acknowledgements:}

This work was supported by the Ministerio de Ciencia y Tecnología (Madrid, Spain) under Projects No. CTQ2005-06446 and CTQ2009-14322. A grant awarded to JJS by the Gobierno de Canarias (Spain) to conduct a research stay at the University of La Laguna is gratefully acknowledged. Thanks are due to Sigma Coatings (Amsterdam, The Netherlands) for providing the coatings.

\section{References:}

1. L.L. Shreir, R.A. Jarman, G.T. Burstein (Eds.), Corrosion, Vol. 2, 3rd edition. Buttherworth-Heinemann, Oxford, 1994, Chapter 14.

2. G. Grundmeier, A. Simões, in: A.J. Bard, M. Stratmann (Eds.), Encyclopedia of Electrochemistry, Vol. 4. Wiley-VCH, Weinheim, 2003, p. 499.

3. T. Nguyen, D. Bentz, E. Byrd, J. Coat. Technol. 66 (1994) 39.

4. R. Feser, M. Stratmann, Werkst. Korros. 42 (1991) 187.

5. J.E.O. Mayne, in: L.L. Shreir, R.A. Jarman, G.T. Burstein (Eds.), Corrosion, Vol. 2, 3rd edition. Butterworth-Heinemann, Oxford, 1994, p. 14:22.

6. A.J. Bard, M.V. Mirkin (Eds.), Scanning Electrochemical Microscopy, Marcel Dekker, New York, 2001.

7. B.R. Horrocks, in: A.J. Bard, M. Stratmann, P.R. Unwin (Eds.), Encyclopedia of Electrochemistry, Vol. 3. Wiley-VCH, Weinheim, 2003, p. 444.

8. R.M. Souto, Y. González-García, S. González, G.T. Burstein, Corros. Sci. 46 (2004) 2621.

9. A.C. Bastos, A.M. Simões, S. González, Y. González-García, R.M. Souto, Prog. Org. Coat. 53 (2005) 177.

10. R.M. Souto, Y. González-García, S. González, Corros. Sci. 50 (2008) 1637.

11. R.M. Souto, Y. González-García, S. González, Prog. Org. Coat. 65 (2009) 435.

12. R.M. Souto, Y. González-García, S. González, G.T. Burstein, Electroanalysis 21 (2009) 2569. 
13. R.M. Souto, Y. González-García, J. Izquierdo, S. González, Corros. Sci. 52 (2010) 748.

14. J.V. Macpherson, P.R. Unwin, in: A.J. Bard, M.V. Mirkin (Eds.), Scanning Electrochemical Microscopy. Marcel Dekker, New York, 2001, p. 521.

15. Y. González-García, G.T. Burstein, S. González, R.M. Souto, Electrochem. Commun. 6 (2004) 637.

16. A.C. Bastos, A.M. Simões, S. González, Y. González-García, R.M. Souto, Electrochem. Commun. 6 (2004) 1212.

17. A.M. Simões, A.C. Bastos, M.G. Ferreira, Y. González-García, S. González, R.M. Souto, Corros. Sci. 49 (2007) 726.

18. C. Bragato, S. Daniele, M.A. Baldo, G. Denuault, Annali di Chimica 92 (2002) 153.

19. S. González, L. Fernández-Mérida, R.M. Souto, Electroanalysis 21 (2009) 2640.

20. R.M. Souto, Y. González-García, S. González, Corros. Sci. 47 (2005) 3312.

21. K. Eckhard, X.X. Chen, F. Turcu, W. Schuhmann, Phys. Chem. Chem. Phys. 8 (2006) 5359.

22. J.P. Hoare, The Electrochemistry of Oxygen. Interscience, New York, 1968.

23. D. Pletcher, S. Sotiropoulos, J. Chem. Soc., Faraday Trans. 91 (1995) 457.

24. A.J. Bard, M.V. Mirkin (Eds.), Scanning Electrochemical Microscopy, Marcel Dekker, New York, 2001, p. 243. 
Figure 1: Cyclic voltammogram measured at the SECM-tip in $0.1 \mathrm{M} \mathrm{Na}_{2} \mathrm{~B}_{4} \mathrm{O}_{7}$ air-saturated aqueous solution. Scan rate: $v=0.1 \mathrm{~V} \mathrm{~s}^{-1}$. It depicts the electrochemical reactions associated with dissolved oxygen in the electrolyte.

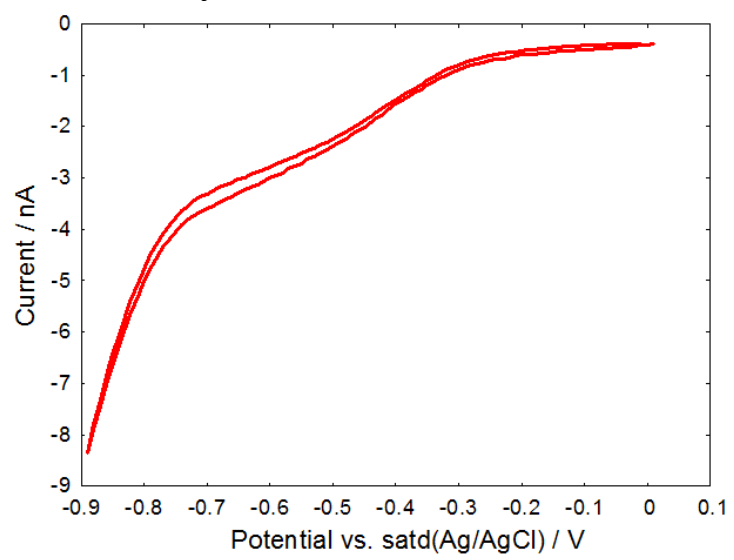

Figure 2: SECM measurements on a polymer-coated carbon steel sample after immersion in $0.1 \mathrm{M} \mathrm{Na}_{2} \mathrm{~B}_{4} \mathrm{O}_{7}$ air-saturated aqueous solution for: (A) $5 \mathrm{~min}$, and (B) $390 \mathrm{~min}$. Tip-substrate distance: $15 \mu \mathrm{m}$. Tip potential: $-0.60 \mathrm{~V}$ vs. $\mathrm{Ag} / \mathrm{AgCl} / \mathrm{KCl}$ (saturated) reference electrode. Scan rate: $30 \mu \mathrm{m} \mathrm{s}^{-1}$. Values of $Z$ axis: Current, nA. The figures represent an area of $1000 \mu \mathrm{m} \mathrm{x}$ $1000 \mu \mathrm{m}$ in $X$ and $Y$ directions.
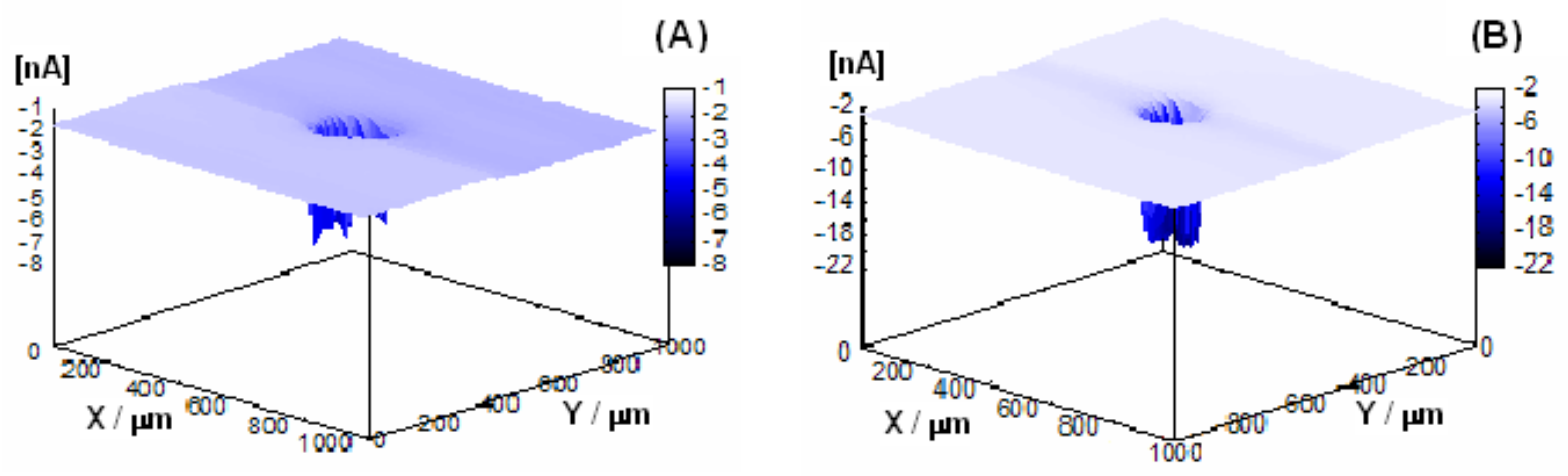

Figure 3: SEM microphotograph of a polymer-coated carbon steel sample after drilling a holiday, previous to exposure in the test electrolyte. A furrow generated during the drilling process can be observed from the holiday upwards.

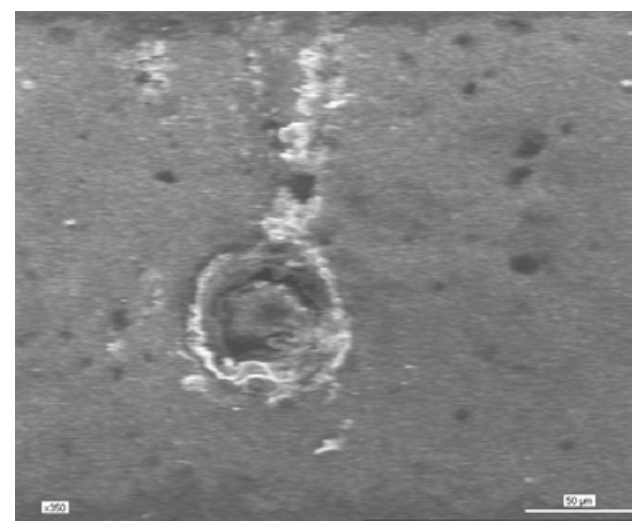


Figure 4: SECM measurements on a polymer-coated carbon steel sample after immersion in $0.1 \mathrm{M} \mathrm{Na}_{2} \mathrm{~B}_{4} \mathrm{O}_{7}$ air-saturated aqueous solution for: (A) $5 \mathrm{~min}$, (B) $170 \mathrm{~min}$, (C) $390 \mathrm{~min}$, (D) $500 \mathrm{~min}$, and (E) 24 hours. Tip-substrate distance: $15 \mu \mathrm{m}$. Tip potential: $-0.60 \mathrm{~V}$ vs. $\mathrm{Ag} / \mathrm{AgCl} / \mathrm{KCl}$ (saturated) reference electrode. Scan rate: $30 \mu \mathrm{m} \mathrm{s}^{-1}$. Values of $Z$ axis: Current, $\mathrm{nA}$. The figures represent an area of $1000 \mu \mathrm{m} \times 10 \mu \mathrm{m}$ in $X$ and $Y$ directions.
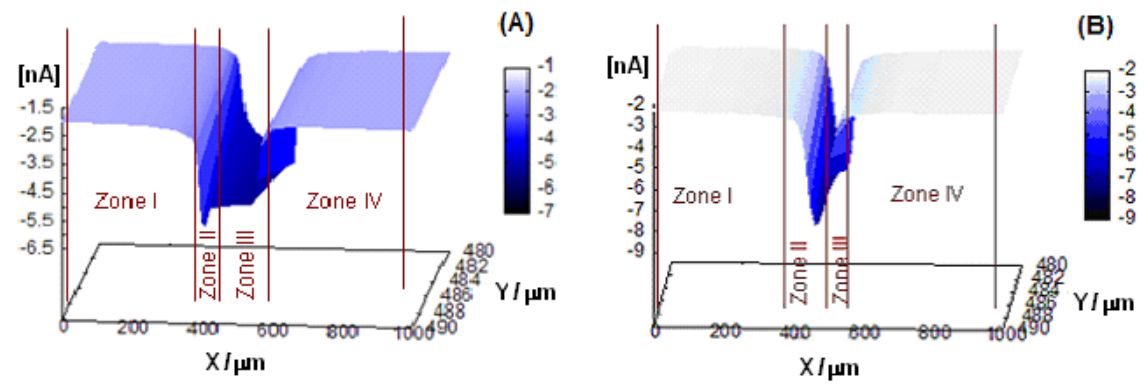

(C)

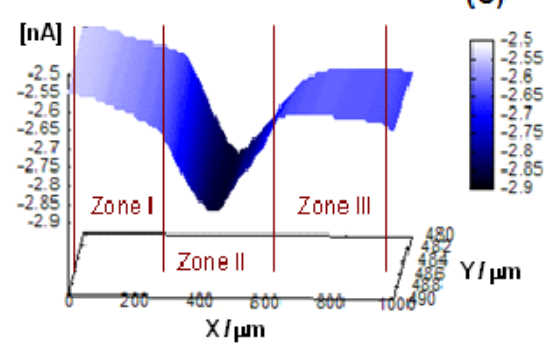

(D)

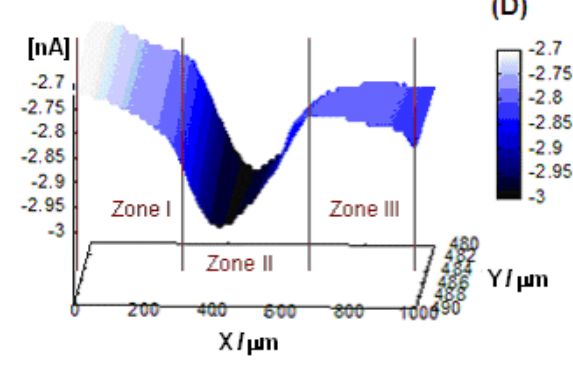

(E)

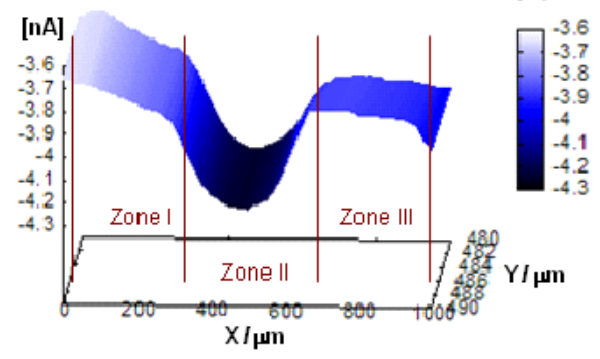

Figure 5: SECM measurements on a polymer-coated carbon steel sample after immersion in $0.1 \mathrm{M} \mathrm{Na}_{2} \mathrm{SO}_{4}$ air-saturated aqueous solution for: (A) $5 \mathrm{~min}$, and (B) $340 \mathrm{~min}$. Tip-substrate distance: $15 \mu \mathrm{m}$. Tip potential: $-0.60 \mathrm{~V}$ vs. $\mathrm{Ag} / \mathrm{AgCl} / \mathrm{KCl}$ (saturated) reference electrode. Scan rate: $30 \mu \mathrm{m} \mathrm{s}^{-1}$. Values of $Z$ axis: Current, nA. The figures represent an area of $1000 \mu \mathrm{m} \mathrm{x}$ $1000 \mu \mathrm{m}$ in $X$ and $Y$ directions.

(A)

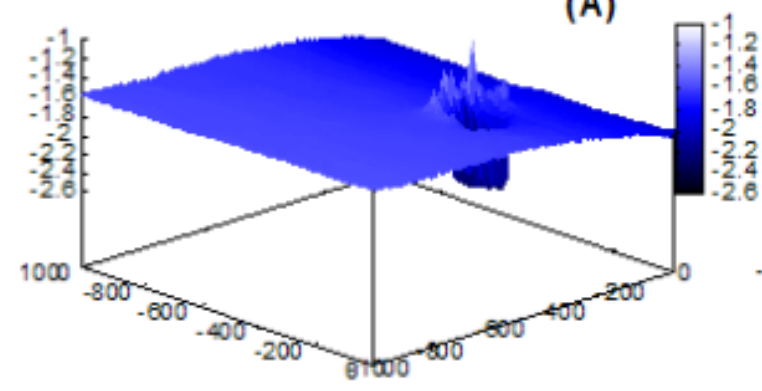

(B)

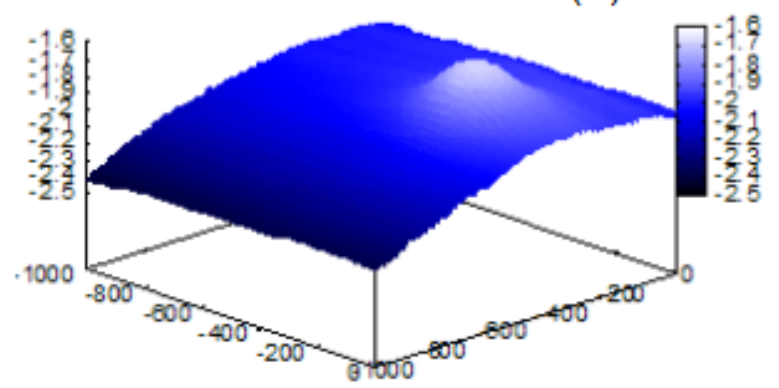


Figure 6: Line scans each representing a single scan of the probe trip across the holiday in the polymer-coated carbon steel sample after immersion in $0.1 \mathrm{M} \mathrm{Na}_{2} \mathrm{SO}_{4}$. Exposure times for each line scan are indicated in the graph.

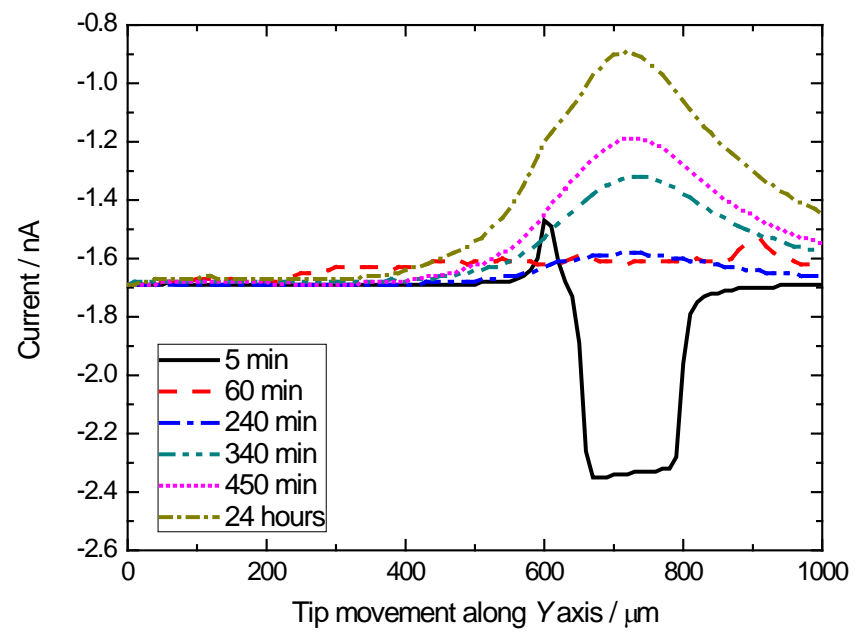

Figure 7: SECM measurements on a polymer-coated carbon steel sample after immersion in $0.1 \mathrm{M} \mathrm{KCl}$ air-saturated aqueous solution for: (A) 5, and (B) $312 \mathrm{~min}$. Tip-substrate distance: $15 \mu \mathrm{m}$. Tip potential: $-0.60 \mathrm{~V} v \mathrm{~s}$. $\mathrm{Ag} / \mathrm{AgCl} / \mathrm{KCl}$ (saturated) reference electrode. Scan rate: 30 $\mu \mathrm{m} \mathrm{s}^{-1}$. Values of $Z$ axis: Current, nA. The figures represent an area of $1000 \mu \mathrm{m} \times 1000 \mu \mathrm{m}$ in $X$ and $Y$ directions.
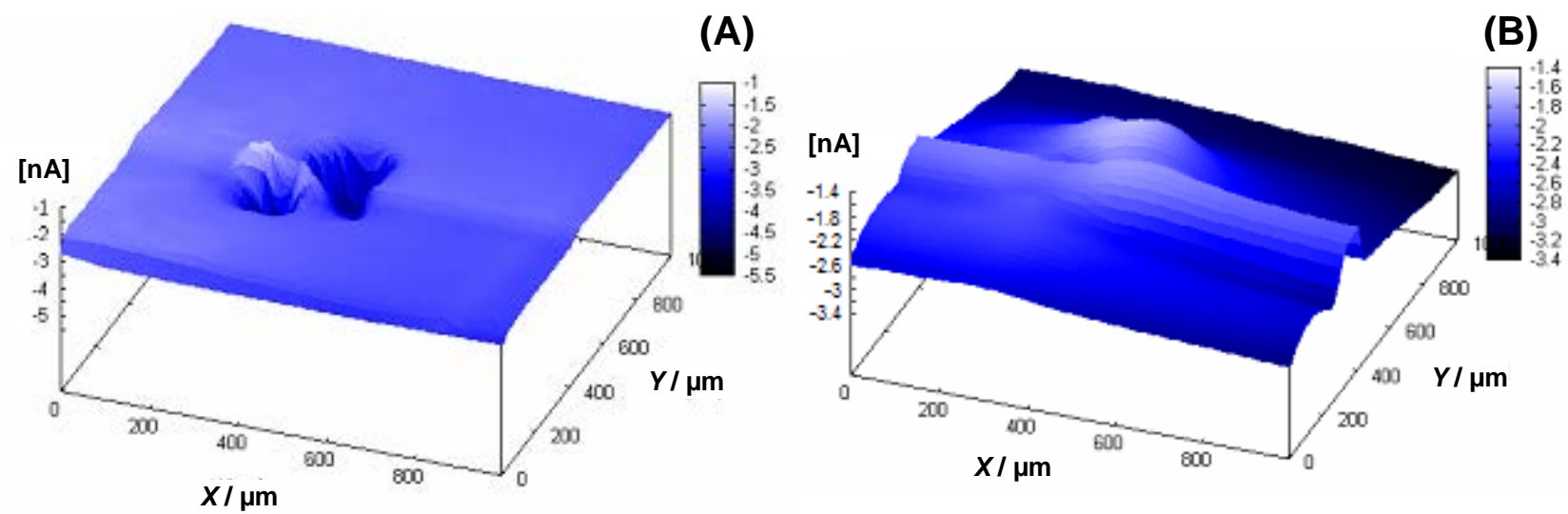
Figure 8: Line scans each representing a single scan of the probe trip across the holiday in the polymer-coated carbon steel sample after immersion in $0.1 \mathrm{M} \mathrm{KCl}$. Exposure times for each line scan are indicated in the graph.

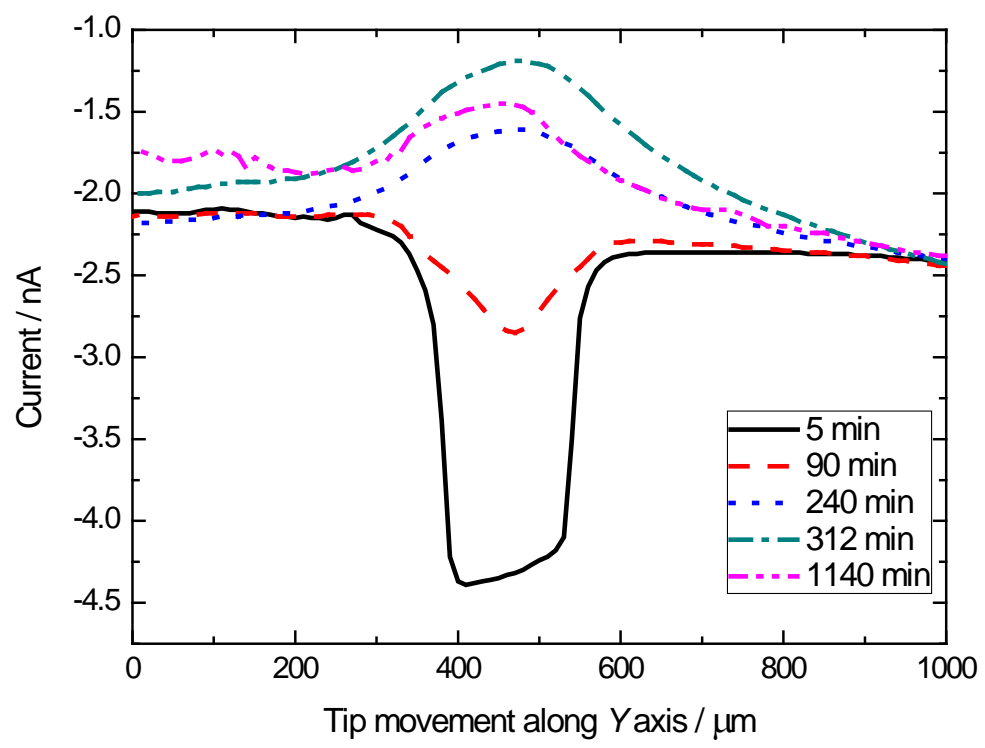

